\title{
COEXISTENT APLASTIC ANAEMIA AND COARCTATION OF THE AORTA
}

\author{
BY \\ J. P. ANDERSON \\ From Bishop Auckland General Hospital
}

(RECEIVED FOR PUBLICATION DECEMBER 19, 1955)

The association of hypoplastic anaemia with congenital abnormalities in children has been recognized since 1927 when Fanconi described three such cases. Several further instances of this Fanconi syndrome have been reported; in each, the congenital anomalies have been multiple and have affected particularly the bones, eyes, genitalia and skin. Only one case has been described (Estren, Suess and Dameshek, 1947) in which cardiovascular abnormality is specifically mentioned: this was an 11-year-old girl with a patent ductus arteriosus and/or atrial septal defect (an exact diagnosis was not made, but the lesion was clearly congenital); she was also undersized, had a pigmented skin, nerve deafness, and bony anomalies of the thumbs, forearm and carpus.

In the following case the hypoplastic anaemia was associated with only one obvious congenital defect, coarctation of the aorta.

\section{Case Report}

A 14-year-old boy attended his doctor with a history of recent severe epistaxes, weakness and exertional dyspnoea. He was pale and had a faint scattered purpuric rash: the heart seemed slightly enlarged and a short apical systolic murmur was heard. Finding some nasal ulceration, his doctor gave a course of sulphamezathine: this proved unhelpful, and the boy was referred to hospital for further medical advice. A provisional diagnosis of thrombocytopenic purpura was made in the out-patient department and the patient was soon admitted for full investigation.

He had always been subject to nose bleeds but these had been worse in the last few weeks. For a year he had bruised easily, and latterly bruises had been appearing spontaneously. He was getting paler. His legs ached, and he had palpitations when he hurried. Previously he had been quite fit. His father and two sisters (aged 6 and 9 years) were well: his mother suffered from occasional attacks of asthma.

He was a short, thick-set boy of normal mentality; he was pale, and had scattered bruises and petechiae over the chest, arms, and trunk; the liver and spleen were not palpable: there was no lymphadenopathy; the blood pressure was $160100 \mathrm{~mm}$. $\mathrm{Hg}$, and there was a systolic murmur over the precordium: the urine was normal: he showed no skeletal, neurological or ophthalmological abnormalities: there was no sign of puberty, and the genitalia were small but normal; the skin was not pigmented.

The blood count showed: Hb $5 \cdot 3$ g. ${ }^{\circ}$, R.B.C. $1 \cdot 31$ millions per c.mm., W.B.C. 1,500 (N. $30^{\circ}$, L. $60^{\circ}$, E. $4 \%$ M. $6 \%$ ); no platelets were seen in the blood film: there was a $2 \%$ reticulocytosis. The bleeding time was over 30 minutes (Duke's method) and the clotting time 5 minutes (Lee and White's method): Hess's tourniquet test was positive; the blood group was $A$ Rh positive. No red bone marrow was obtained with a sternal puncture, but an iliac crest puncture was more successful. The marrow was very sparsely cellular: the granulocytes showed primary aplasia and maturation arrest at the myelocyte-metamyelocyte level; the red cell precursors were reduced in number but were maturing normally: no megakaryocytes, and no cells more immature than premyelocytes or proerythroblasts, were seen.

A diagnosis of aplastic anaemia having been made, the boy was given a transfusion of packed red cells. He improved considerably, and was allowed home. Oral iron and proteolysed liver were ordered.

Less than a week later he was readmitted with more petechiae and increasing pallor. The blood count had fallen, and a further packed cell transfusion was given. During his stay a detailed examination was made of the cardiovascular system: this revealed unequivocal evidence of coarctation of the aorta. No abdominal aortic pulsation and none of the leg pulses were palpable; the systolic blood pressure was $145 \mathrm{~mm} . \mathrm{Hg}$ in each arm, $95 \mathrm{~mm}$. $\mathrm{Hg}$ in the right leg and $90 \mathrm{~mm}$. $\mathrm{Hg}$ in the left: pulsation could be felt and heard in the suprascapular and superficial epigastric arteries. The heart was slightly enlarged, and a grade 3 murmur could be heard, closely following the first heart sound, over the precordium, down the spine, and over the palpable vessels. There was no evidence of aortic regurgitation. A chest radiograph showed slight left ventricular enlargement, a dilated ascending aorta, no aortic knuckle, and 'notching' of the fourth, fifth, sixth and seventh ribs posteriorly. The immediate management of the case 
was unaffected by these findings, and the boy was obliged to attend regularly for blood transfusions, 3 pints of blood being required every two or three weeks. At no time was there any evidence of spontaneous improvement in the pancytopenia. Nevertheless, the boy was able to lead a fairly normal life.

Although the two pathological conditions were presumed to be unrelated, there was a possibility that subacute bacterial endocarditis could be the link between them. A persisting evening pyrexia was an additional reason for investigation. Successive blood cultures were negative, however, and the boy's good general condition, appetite and vitality were well maintained.

The clinical course was punctuated after four months by a very severe epistaxis for which he required repeated nose-packing and a total of 11 pints of blood. Six months later, two series of severe epistaxes required the transfusion of 16 additional pints of blood. The end came a few weeks afterwards, when the boy suddenly began vomiting and became unconscious, with signs of cerebral haemorrhage. He died two hours later without regaining consciousness. He had survived 12 months from the date of diagnosis, and during that time had received a total of 86 pints of blood. (It is a remarkable tribute to the laboratory staff that, despite the large number of transfusions, no reactions occurred and no irregular antibodies were ever detected by the albumin tube or Coombs tests.)

The post-mortem examination showed a large left cerebral haemorrhage, multiple small scattered haemorrhages in nearly all the organs and a typical severe adult-type aortic coarctation without other congenital cardiovascular defects. The marrow cavity of the right femur contained only soft yellow fatty tissue. At death, the boy was 15 years 4 months old; he was $5 \mathrm{ft}$. 2 in. in height and showed no signs of puberty. Otherwise he was of normal physical and mental development.

\section{Comment}

This association of pancytopenia with aortic coarctation could be considered merely coincidental, but as Reinhold, Neumark, Lightwood and Carter (1952) point out, 'Aplastic anaemia (in children) ... is sufficiently rare to make an association with other congenital malformations by chance a remote possibility.' The moderate underdevelopment of the skeleton and genitalia in the present case may have been significant in the circumstances. Admittedly, the child showed no microcephaly, localized bone anomalies, squint, mental defect, spasticity, renal abnormality, pigmentation, gynaecomastia or other peculiarities, and his two sisters are quite normal children. Thus he clearly did not fall within the generally accepted bounds of the Fanconi syndrome (Estren and Dameshek, 1947; Reinhold et al., 1952). But it does seem possible that he represented a sporadic forme fruste of this condition, there being an incomplete manifestation of the inherent chromosomal defect postulated by Fanconi. An alternative possibility - remote, but important from the practical standpoint-was that the pancytopenia could have been a manifestation of occult subacute bacterial endocarditis (Parsons, Cooper and Scheifley, 1953). But the clinical, bacteriological and (later) pathological findings excluded this.

It seems most unlikely that 'partial ischaemia' of the centres of haemopoiesis (which nearly all lie distal to an aortic coarctation) could have been a factor in the pathogenesis of the hypoplastic anaemia. But the two primary conditions doubtless acted synergically in at least two ways: the tendency to epistaxis, and the final cerebral haemorrhage (a common cause of death in both).

My thanks are due to Dr. Frank Robertson for permission to publish, and to Dr. J. M. Robertson for the pathological reports.

\section{REFERENCES}

Estren, S. and Dameshek, W. (1947). Amer. J. Dis. Child., 73, 671. Suess, J. F. and Dameshek, W. (1947). Blood, 2, 85.

Fanconi, G. (1927). Jb. Kinderheilk., 117, 257.

Parsons, W. B., Cooper, T. and Scheifley, C. H. (1953). Ann. intern. Med., 39, 318.

Reinhold, J. D. L., Neumark, E., Lightwood, R. and Carter, C. O. (1952). Blood, 7, 915. 